Review

\title{
The Status of Pollutants in the Three Gorges Reservoir Area, China and its Ecological Health Assessment
}

\author{
${ }^{1, \dagger}$ Chun-Jiao Lu, ${ }^{1,2, \dagger}$ Dan Luo, ${ }^{1,3}$ Muhammad Junaid, ${ }^{2}$ Jin-Jing Duan, \\ ${ }^{2}$ Shi-Min Ding, ${ }^{1,2}$ Ao-Xue Dai, ${ }^{2}$ Tuan-Wu Cao and ${ }^{1}$ De-Sheng Pei \\ ${ }^{1}$ Chongqing Institute of Green and Intelligent Technology, Chinese Academy of Sciences, Chong Qing 400714, China \\ ${ }^{2}$ Yangtze Normal University, Chong Qing 408100, China \\ ${ }^{3}$ University of Chinese Academy of Sciences, Beijing 100049, China
}

Article history

Received: 05-06-2016

Revised: 01-09-2016

Accepted: 15-09-2016

Corresponding Author:

De-Sheng Pei

Chongqing Institute of Green

and Intelligent Technology,

Chinese Academy of Sciences,

Chong Qing 400714, China

Email: peids@cigit.ac.cn; deshengpei@gmail.com

$\dagger$ These authors contributed equally to the manuscript.

\begin{abstract}
The Three Gorges Reservoir Area (TGRA) stretches along the Yangtze River from Jiangjin District, Chongqing to Yichang, Hubei in China. Since TGRA is the main source of drinking water and fresh fishery in China for millions of people, both researchers and the government have concerns for environmental pollution and ecological security in the TGRA. This review highlighted the status and trends of primary water pollutants/parameters in the TGRA and evaluates their impacts on its ecological health for nearly 12 years. In this study, we analyzed the published data including the bulletin on the ecological and environmental monitoring results of the three gorges project, statistical yearbook data from years 2004 to 2015 and published articles. Chemical indicators model was applied to elucidate the ecological health of TGRA based on nitrogenous compounds, phosphorus compounds, organic reducing substances, volatile phenol and heavy metals $(\mathrm{Cr}, \mathrm{Cd}, \mathrm{Cu}, \mathrm{Hg}, \mathrm{As}$ and $\mathrm{Zn}$ ). The results showed that the ecological health conditions slightly varied during these years in the TGRA. Moreover, the value of ecological health in spring, summer and autumn was lower than that in winter. Generally, the overall ecological health of the TGRA during these 12 years seems to be stable. Although the ecological health of TGRA is good, there is an urgent need to strictly implement the industrial discharges standards to assure the ecological integrity and sustainable development of the TGRA.
\end{abstract}

Keywords: Chemical Indicators Model, Heavy Metals, Seasonal Variations, Wastewater, Yangtze River

\section{Introduction}

The Three Gorges Reservoir Area (TGRA) is located between $106^{\circ} 20^{\prime}-110^{\circ} 30^{\prime}$ east longitude and $29^{\circ}-31^{\circ} 50^{\prime}$ north latitude, with a total area of about 599 square kilometers (Zhou, 2006), including the Hubei province and populous Chongqing city with 30 million people (Yan et al., 2011)(Fig. 1). Construction and operation of the Three Gorges Dam (TGD) imposed threats to sediment stability, aquatic fauna immigration, as well as other environmental and ecological influences (Wei et al., 2009). The focal point is unregulated and untracked water pollutants from non-point sources and their influxes to Yangtze River.

The current article is an effort to mine related data and statistically analyze the reported studies about basic water pollutants, their sources, proportions and trends of water quality in the TGRA. The literature search was performed on the basis of the three gorges project monitoring bulletin from 2004 to 2015, statistical yearbook and relevant journal articles. Moreover, this review will provide the gist of the ecological health, discharges control and management of the natural resources in the TGRA.

\section{Dynamics of Wastewater Pollution in the TGRA}

\section{Domestic and Industrial Wastewater}

In the TGRA, water pollutants mainly come from industrial wastewater, domestic wastewater and 
agricultural discharges along with other point and nonpoint sources. According to the reported data (SEPA, 2004-2015), the TGRA was a sink for 11.371 billion tons of pollutants from 2003 to 2014. The industrial and domestic wastewater accounted for 37.25 and $62.75 \%$ of the wastewater drained into the TGRA, respectively. The major classes of pollutants in the drained wastewater were volatile hydroxybenzene, petroleum traces, heavy metal, nitrogen-containing compound, phosphorous compound, organic matter, ferrous salt, nitrites and sulfide compounds. Fig. 2 showed (1) the amount of annual wastewater drainage from industrial and domestic wastewater and (2) the variation of $\mathrm{COD}$ and $\mathrm{NH}_{3}-\mathrm{N}$ concentration in wastewater from year 2003 to 2014 in the TGRA. The line graph illustrated that the discharges of domestic wastewater expressed a stable trend from 2005-2010 and then gradually increased until recently. The reasons could be rapid urbanization and increase in population. Industrial wastewater discharges trend was increased in the start from 2003-2007 and then stabilized similar to the sanitary discharges, albeit it decreased and leveled off after 2010 , contrary to the sanitary discharges. From 2003 to 2007, the industrial wastewater discharges increased year by year. From 2008 to 2014, industrial wastewater discharges seemed to be under control. The energy-intensive, highly polluting industrial sectors were relocated to other small districts around Chongqing city and transformed under strict regulation, which played critical role in controlling wastewater influxes to the TGRA. Wastewater quality control is also closely associated with the industrial production and processing technology. There is an urgent need to maintain the control of the industrial discharges and urban sewage to assure the water quality of TGRA (Constanza et al., 1997).

\section{The Trend of COD}

Generally, COD means under certain conditions, the amount of dissolved oxygen consumed by reducing substance in $1 \mathrm{~L}$ water. The COD contains ferrous salt, nitrite, sulfur and organic matter, ect. COD is a comprehensive indicator for water quality. Untreated domestic wastewater and industrial wastewater usually possess high COD level because of abundant reducing substances (SEPA, 2002). The COD discharges of industrial wastewater and domestic wastewater in the TGRA reached 1.9842 million tons from 2003 to 2014 . Domestic wastewater was accounted for $68.21 \%$ of the total COD (Fig. 2). From the COD trend, the content of COD in industrial wastewater for recent 12 years showed little change and the discharges rates variated between 0.01-0.019\%,with a slight decline in 2004 (Fig. 3). Discharges mainly come from the chemical industry, food manufacturing industry and paper industry, which were probably the main source of COD in the TGRA. The COD trends of domestic wastewater were the same as of industrial discharges. The COD content of sewage discharges first declined and then increased. This could be the consequences of the urbanization of TGRA and local development related activities and also could link with the overall economic development and improved household living standard. Before the completion of the Three Gorges project, the organic matter content in reservoir was reduced. The reviewed data in current study largely presents the pre-TGD impoundment pollutants status and trends. Therefore, post-TGD operation environmental monitoring studies are highly recommended to explore the ecological integrity, due to continuous pollutants storage in sediments and large quantity of relatively stagnant water in the TGRA near the dam.

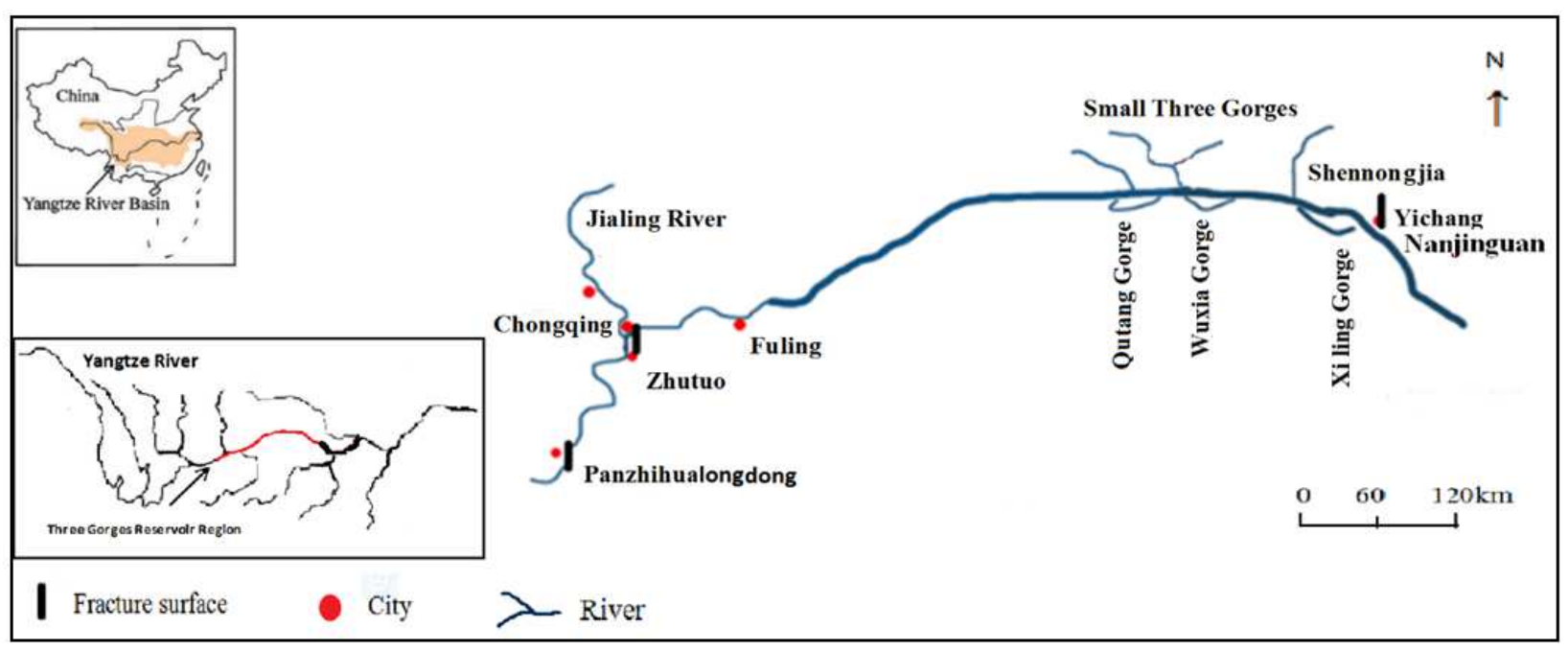

Fig. 1. The Three Gorges Reservoir Area (TGRA) of the Yangtze River 


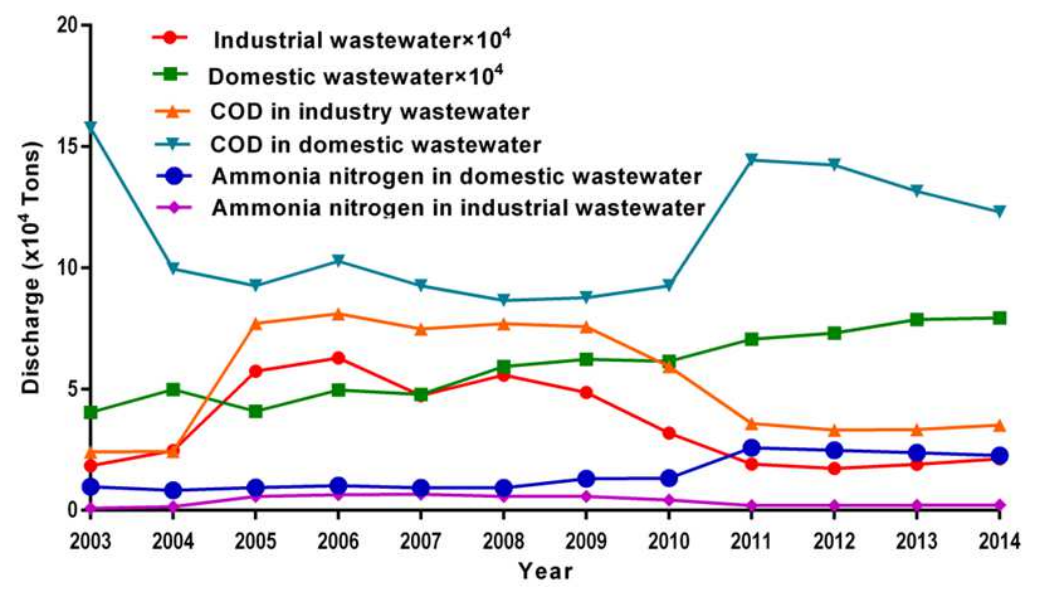

Fig. 2. The annual comparison of domestic and industrial wastewater discharge, $\mathrm{COD}$ and $\mathrm{NH}_{3}-\mathrm{N}$ from year 2003 to 2014 in the TGRA (SEPA, 2004-2015)

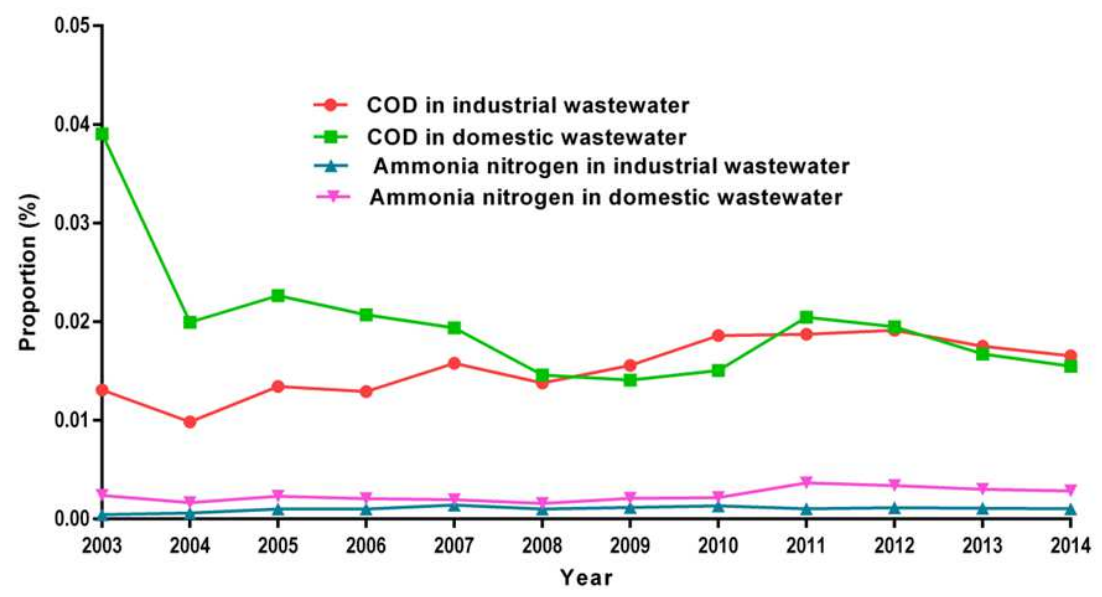

Fig. 3. The percentage contribution of $\mathrm{COD}$ and $\mathrm{NH}_{3}-\mathrm{N}$ in industrial and domestic wastewater from year 2003 to 2014 in the TGRA (SEPA, 2004-2015)

\section{The Trend of $\mathrm{NH}_{3}-\mathrm{N}$}

Ammonia nitrogen is a major parameter to assess the health of water bodies. Commonly, $\mathrm{NH}_{3}-\mathrm{N}$ is an essential nutrient for aquatic phytoplankton. When the content of nitrogen in water exceeds the normal requirement, it may lead to phytoplankton blooms and cause the state of eutrophication. The ammonia nitrogen in the TGRA mainly comes from industrial wastewater, domestic wastewater and agricultural discharges. As illustrated in Fig. 3, the content of $\mathrm{NH}_{3}-\mathrm{N}$ in industrial wastewater and domestic sewage reached 224,700 tons over the past 12 years (Yang, 2013), i.e. about $0.002 \%$ of the total wastewater. The concentration trend of $\mathrm{NH}_{3}-\mathrm{N}$ indicated that the $\mathrm{NH}_{3}-\mathrm{N}$ levels in domestic wastewater were higher over the years, compared to that of industrial wastewater. The increase of $\mathrm{NH}_{3}-\mathrm{N}$ content in the domestic wastewater was closely associated with the increase of the domestic wastewater discharges. From 2003 to 2008 the ammonia nitrogen discharges was relatively stable and then began to increase. The possible reasons could be similar to that of increased COD levels. The variation in $\mathrm{NH}_{3}-\mathrm{N}$ trend in industrial wastewater discharges over the 12 years were observed stable (Fig. 3).

\section{The Status of Heavy Metal in the TGRA}

Heavy metals refers to the metals with density more than 4 or $5 \mathrm{~g} / \mathrm{cm}^{3}$, such as $\mathrm{Cr}$, As and Se and their chemical properties are similar to common metals but biological toxicity could be many folds higher. This kind of pollutants are mostly biologically nonbiodegradable and can accumulate and transfer to a higher level of the food chain. Transformation of heavy metals to other oxidation states and their migration mainly relies on complex processes of sorption, desorption and ligand formation etc. The heavy metals dissolved in the water or adsorbed on the sediment are 
of great importance, because they enhance the surface area and become readily available. Therefore, understanding the level of heavy metals in fresh water bodies is of great significance and influences the evaluation of ecological health. There are many heavy metals reported in the mainstream and tributaries of TGRA, such as $\mathrm{Hg}, \mathrm{Cd}, \mathrm{Cu}, \mathrm{Pb}$, As, etc. However, $\mathrm{Hg}$ level is of special concern because of the mercury mines in Chongqing region and Wuling district.

Previous studies reported the heavy metals contamination and distribution in Taiping River, Guandukou, Tuokou, Qingxichang and Cuntan as monitoring points of the TGRA (Yang, 2013; Wang et al., 2013). Other studies also discussed the presence of heavy metals traces in river tributaries, such as Xiangxi river, Rangdu river, Ruxi river, Xiaojiang, Huangjin river, Mei River, Daning river, Shennong brook, Tongzhuang river and Lixiang brook (Zhang and Zhang, 2004; Wang et al., 2004). These later 10 tributaries significantly impacted the metal concentrations in the mainstream river. Recent studies showed that different heavy metals, such as $\mathrm{Hg}, \mathrm{Cd}, \mathrm{Cu}$ and $\mathrm{Pb}$ existed in the TGRA and their concentrations were within the range of the quality standards for surface water (Wang et al., 2013; Zhang and Zhang, 2004). In the mainstream of TGRA, the amount of $\mathrm{Hg}$ in the sediments and suspended solids ranged 0.00001-0.00004 $\mathrm{mg} \mathrm{L}^{-1}$ and 0.1572-0.2507 $\mathrm{mg} \mathrm{Kg}^{-1}$, respectively. The monitoring points in Chongqing close to Wuling and Xiushan mercury mine area exhibited relatively higher $\mathrm{Hg}$ content, compared to other heavy metals. $\mathrm{Hg}$ can easily bio-accumulate in aquatic organisms, thus, the $\mathrm{Hg}$ content in human may increase due to food chain contamination. In the TGRA water, the reported concentrations of $\mathrm{Cd}, \mathrm{Cu}$ and $\mathrm{Pb}$ were ranged 0.0010 $0.0027,0.005-0.077$ and 0.01-0.063 $\mathrm{mg} \mathrm{L}^{-1}$, respectively. However, the concentration of As was < $0.007 \mathrm{mg} \mathrm{L}^{-1}$. The content of $\mathrm{Cu}$ in sediment and suspended solids was found from 36.46 to $89.67 \mathrm{mg}$ $\mathrm{Kg}^{-1}$. The content of $\mathrm{Pb}$ or As was ranged from 38.08 to 89.30 or 15.39 to $16.23 \mathrm{mg} \mathrm{Kg}^{-1}$, respectively. Most of the heavy metals were reported with low concentrations in the tributaries water, such as the concentrations of $\mathrm{Hg}, \mathrm{Cu}$ and $\mathrm{Pb}$ were below detection limits. The concentration of $\mathrm{As}$ at each of the monitoring sections were reported between 0.0003 to $0.0034 \mathrm{mg} \mathrm{L}^{-1}$ (Yang, 2013; Zhang and Zhang, 2004).

There are many factors influencing the water solubility of metals, such as $\mathrm{pH}$, water temperature, oxidation reduction potential, suspended solids, ect. According to the literature, the content of dissolved heavy metals in the wet season is higher than dry season (Wang et al., 2013). During the wet season, the $\mathrm{pH}$ of water falls and the hydrogen ion concentration in the water increases (Zhang and Zhang, 2004; Zhang et al.,
2014). Thus, the competitive ability of hydrogen ions is increased, which can lead to the solubility of more heavy metals from suspended solids. The concentration of dissolved heavy metal in the main stream was higher than that in the tributaries and the content of heavy metal in tributary sediment was higher than that in mainstream water.

\section{The Status of Total Phosphorus (TP) in the TGRA}

The phosphorus sources in the TGRA can be divided into exogenous and endogenous sources. Exogenous sources mainly include the domestic wastewater discharges, industrial effluents, irrigation and drainage, etc (Benitez-Nelson, 2000). Endogenous sources mainly refer to the release from sediment and suspended sediment particulate matter (SPM). The Total Phosphorus (TP) of TGRA mainly comes from domestic wastewater, farmland drainage, fertilizer and detergent, etc. Phosphorus is one of the essential elements for the growth of aquatic organisms (Benitez-Nelson, 2000; Liu, 2007). Phosphorus plays a critical role in the eutrophication of water bodies. In the water environment, TP mainly includes the dissolved total phosphorus, total particulate phosphorus (Liu, 2007; Zhang et al., 2014). Dissolved total phosphorus include dissolved inorganic phosphorus and dissolved organic phosphorus. The orthophosphate is the main form of the dissolved inorganic phosphorus and phosphate ester is the form of the dissolved organic phosphorus. Total Particulate Phosphorus (TPP) is the mainly composed of particle inorganic phosphorus and particle organic phosphorus (Liu, 2007; Shen and Shi, 1996). Reports showed that phosphorus mainly existed in the form of particles state in the TGRA ( $\mathrm{Xu}$ et al., 2004). The content of particulate phosphorus is closely related to the suspended sediment concentration and particle size in the water (Xu et al., 2004). Analyzed data revealed that the construction of TGD and the settlement of coarse particle led to decline in particle size $(\mathrm{Xu}, 2005)$, which resulted in higher adsorption rate of phosphorus (Hong et al., 2004; Lin and $\mathrm{Wu}$, 1994). When the phosphorus level is higher than the capacity level, it may lead to water eutrophication. A large number of plankton, such as algae, feed on phosphorus and become dominant in the water body. They consume dissolved oxygen in water and create anoxic conditions for other aquatic organisms. Consequently, water eutrophication could worsen water quality and disturb the normal growth conditions.

From 1997 to 2003, the amount of TP during the low-water level in the TGRA was $0.114 \mathrm{mg} \mathrm{L}^{-1}$, the normal-water level was $0.121 \mathrm{mg} \mathrm{L}^{-1}$ and the highwater level was $0.128 \mathrm{mg} \mathrm{L}^{-1}$ (Yin and $\mathrm{Li}, 2014$ ). 
From 2004 to 2010, the amount of TP during the lowwater level in the TGRA was $0.1 \mathrm{mg} \mathrm{L}^{-1}$, the normalwater level was $0.109 \mathrm{mg} \mathrm{L}^{-1}$ and the high-water level was $0.122 \mathrm{mg} \mathrm{L}^{-1}$ (Yin and Li, 2014). The concentrations of TP in the tributaries were 0.035-0,65 $\mathrm{mg} \mathrm{L}^{-1}$, with the average of $0.157 \mathrm{mg} \mathrm{L}^{-1}$ (Liu and Yin, 2014). The concentrations of TP reached the highest level from June to September (high-water period) every year (Wen and Liu, 1996). From 1997 to 2010 , the variation in TP level of TGRA was not significant, albeit higher than that of surface water. The TP level in tributaries exceeded the main stream levels and both levels were above permissible limits of the surface water (Wen and Liu, 1996; Lu and Mi, 2011). Endogenous phosphorus is mainly derived from the release of sediments and suspended solids. TP concentrations reached the highest level from June to September every year, which is possibly attributed to the increase of suspended matter in the water and decrease in their adsorption capacity.

\section{The Status of Ecosystem Health in the TGRA}

\section{Chemical Index Method (CIM)}

With the rapid industrialization in China, environmental and ecological problem are also rising at the same pace (Xiong et al., 2010; Wells, 2003; Silow and In-Hye, 2004). In the same manner, researchers are more interested in elucidating the ecological health status of lakes, rivers and other fresh water bodies (Xu and $\mathrm{Xu}, 2007$; Ye et al., 2007). Recently, the evaluation methods of ecosystem health mainly include index system method and the indicator species method (Grilfitth et al., 2005; Lu et al., 2015). The index system method is devised according to the characteristics and function of the river. However, indicator species method utilizes some kind of composition, distributions of structure and biomass and richness etc, to evaluate river ecological health. In this review, we applied the chemical index system to evaluate the ecological health of TGRA for nearly 12 years. The results will help to understand the current status of ecosystem health and the ecological integrity of TGRA over the years.

\section{Selection of Indices for Chemical Index Method}

Based on chemical index method to evaluate the ecosystem health of TGRA (Yan, 2007; Yan et al., 2008), we selected pH, Dissolved Oxygen (DO), $\mathrm{COD}_{(\mathrm{Mn})}$ and $\mathrm{NH}_{3}-\mathrm{N}$ as indices according to previous studies (Liao et al., 2014; Xie et al., 2014). $\operatorname{COD}_{(\mathrm{Mn})}$, $\mathrm{pH}, \quad \mathrm{DO}$ and NH3-N are basic and important parameters to monitor water quality and organic activity. Secondly, there is paucity of data related to emerging pollutant, such as PCPPs, PAHs and POPs, thus we selected continuously available parameters from 2004-2015. The $\mathrm{pH}$ greatly influences chlorophyll a, heavy metals, nitrogen and phosphorus (Ma et al., 2001; Huang et al., 2011). The change of DO is very important for oxygen balance in water (ACEDP, 2012; Hellawell, 1986), which can be disturbed by the contents of COD $(\mathrm{Mn})$ and $\mathrm{NH}_{3}-\mathrm{N}$. The classification of ecological health indices on the basis of chemical index model is presented in Table 1 .

\section{Trends of Ecosystem Health in Recent 12 Years}

We evaluated the ecological health status of TGRA from year 2004-2015 by using the chemical factors. The selected monitoring sections in the TGRA were Longdong (Panzhihua, Sichuan, the upper stream of TGRA), Zhutuo (Yongchuan, Chongqing; the middle stream of TGRA with high population density and industrial area), Nanjinguan (Yichang, Hubei; the downstream of TGRA close to the Three Gorges Dam) (Fig. 1). Afterwards, according to the ministry of environment protection reports on water quality of the Yangtze River, we calculated the chemical indicators to assess the ecosystem health according to the below adapted formula (SEPA, 2004-2015; Cui et al., 2012):

$$
X_{i}^{\prime}=\frac{X_{i}-X_{\min }}{X_{\max }-X_{\min }}
$$

where $X_{\max }$ and $X_{\min }$ indicates the maximum and the minimum values; $X_{i}$ indicates each single data point.

The trends of ecological health in Longdong, Zhutuo and Nanjinguan were shown in Fig. 4 from 2004 to 2015. The ecological health of Zhutuo appeared to be more at stake than the reservoir area with lowest index value of 0.469 in summer of 2008 , which represents fair ecological health according to health indices classification system (Table 1) in this section. According to the primarily evaluated data, reasons might be the influx of high wastewater loads in Zhutuo region of the reservoir area. Nanjinguan showed stable ecological health indices values because of its location at the edge of the Three Gorges Dam (Fig. 4). In general, calculated health indices for other three sections i.e. Longdong, Zhutuo and Nanjinguan didn't show significant variations in ecological health in the past 12 years (Fig. 5). Ecological disturbance was reduced and relatively more stable after the construction of dam. The value of ecological health in spring, summer and autumn was slightly lower than that in winter in the three evaluated locations (Fig. 6), albeit the overall health status is good. 
Table 1. The classification for health index based on Chemical Evaluation Indices Model (CIM)*

\begin{tabular}{lllll}
\hline Bad & Poor & Fair & Good & Excellent \\
\hline $0-0.2$ & $0.2-0.4$ & $0.4-0.6$ & $0.6-0.8$ & $0.8-1.0$ \\
\hline
\end{tabular}

*The Calculation method of chemical evaluation indexes: $X_{i}^{\prime}=\frac{X_{i}-X_{\min }}{X_{\max }-X_{\min }}$.

where $X_{\max }$ and $X_{\min }$ indicates the maximum and the minimum values; Xi indicates each single data point. $X_{i}^{\prime}$ indicates the health index of each point.
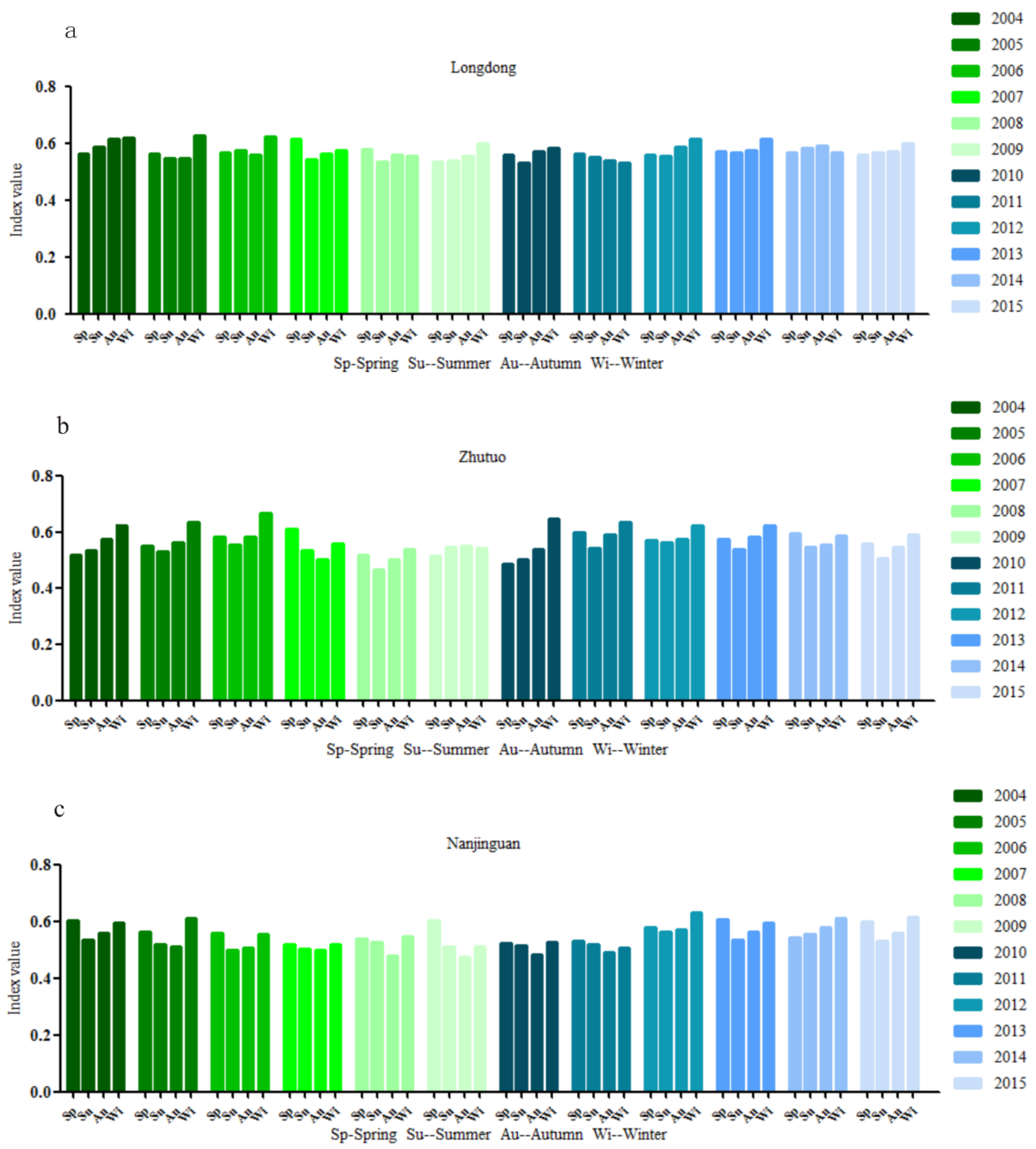

Fig. 4. The trends of ecological health in three sites of TGRA from 2004 to 2015. (a)Longdong; (b)Zhutuo and (c)Nanjinguan 


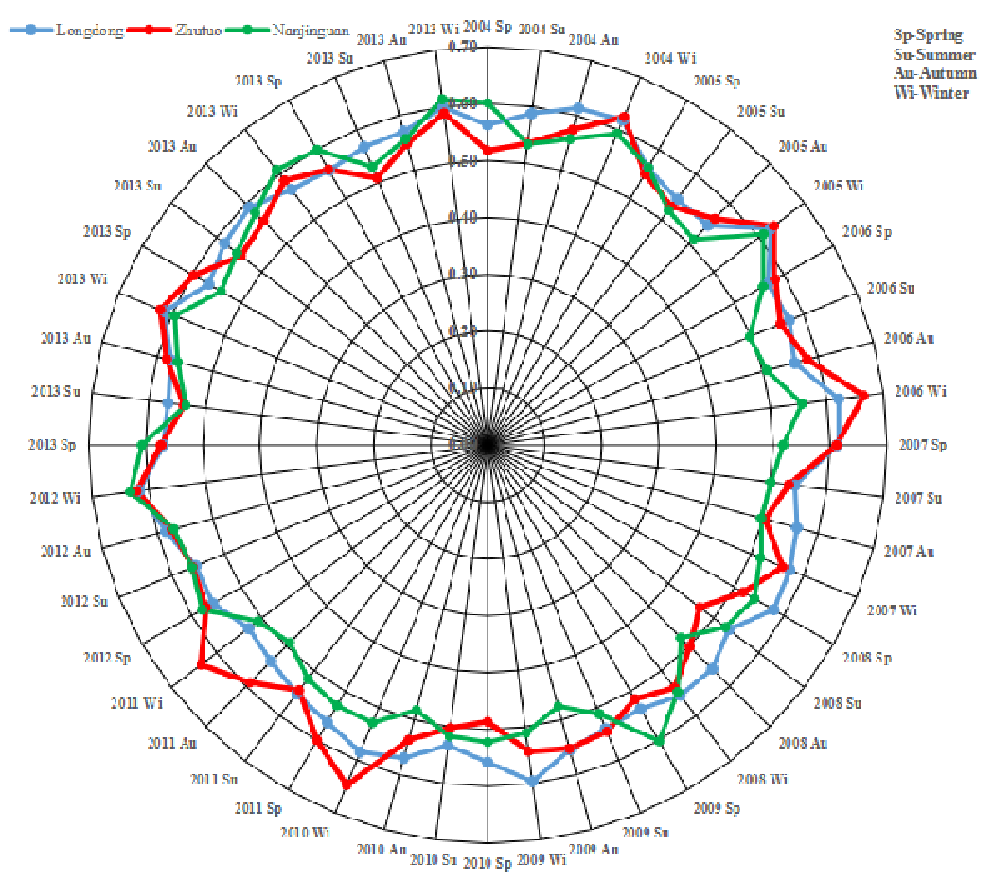

Fig. 5. The radar diagram representing the seasonal variationsin ecological health status in Longdong, Zhutuo and Nanjinguan from 2004 to 2015
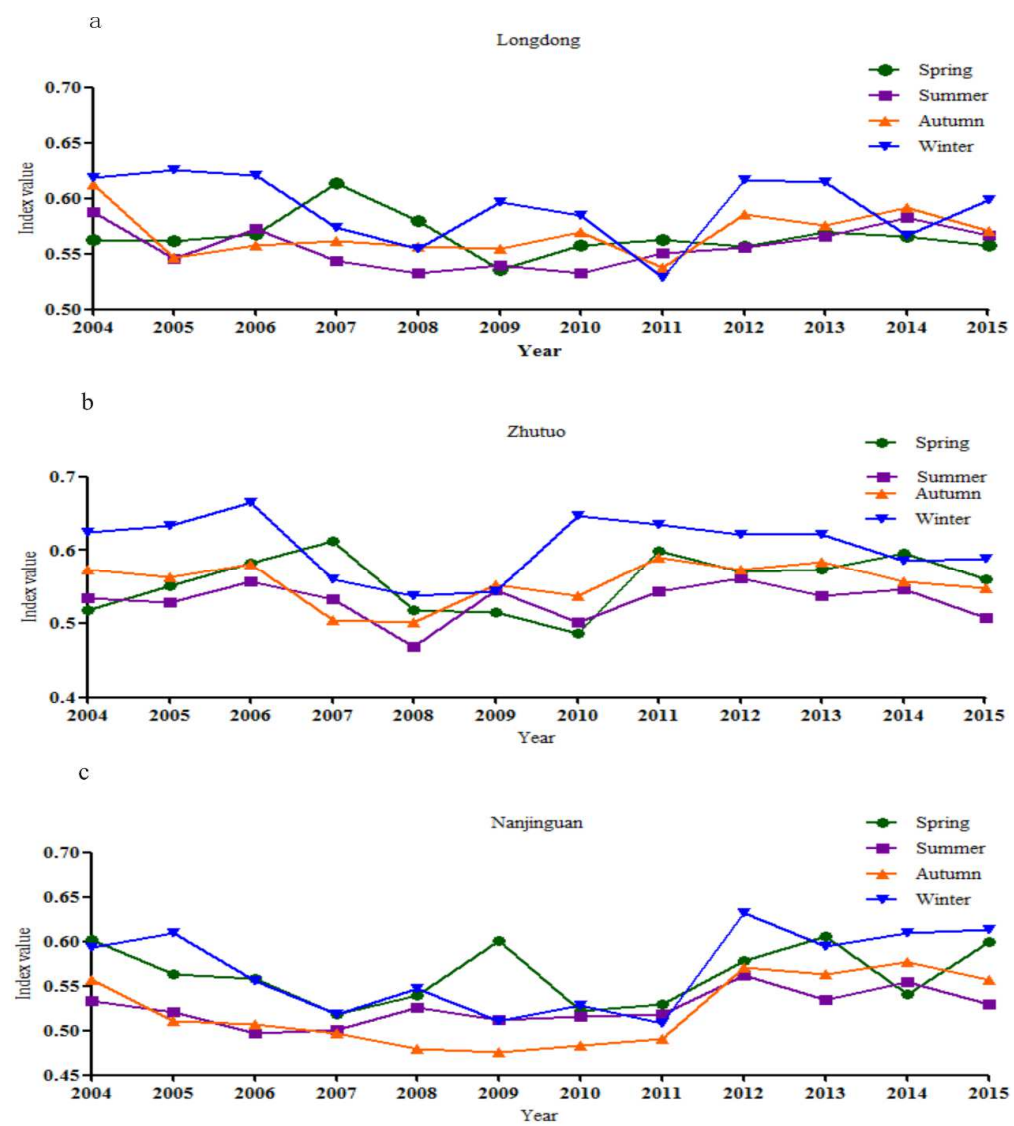

Fig. 6. The seasonal variations and trends of ecological health in three sites of TGRA from 2004 to 2015. (a) Longdong; (b) Zhutuo; (c) Nanjinguan 


\section{Concluding Remarks}

This review encompasses the evaluation of the ecological and environmental health status of TGRA for recent 12 years on the basis of basic water pollutants and water quality parameters reported in literatures. According to the analyzed data, industrial and urban domestic sewage are the major source of pollutants in the TGRA. From 2003-2014, industrial wastewater discharges first increased, then decreased gradually and stabilized, but $\mathrm{COD}$ and $\mathrm{NH}_{3}-\mathrm{N}$ discharges remained stable due to the reduction of high energy consumption and the renovation of high pollution enterprises. Although municipal sewage discharges volume increased year by year, the trends of $\mathrm{COD}, \mathrm{NH}_{3}-\mathrm{N}$ discharges in domestic wastewater showed slight variation. In Chongqing region and Wuling district the levels of $\mathrm{Hg}$ were higher because of the presence of $\mathrm{Hg}$ mines in surroundings. TP concentrations reached the highest level in June-September every year. The evaluation of the ecosystem health in the TGRA by chemical indicators showed that Ecosystem Health Comprehensive Index (EHCI) in the Nanjinguan is slightly lower than Longdong and Zhutuo. However, the status of ecological health in three sites showed slightly lower trend in spring, summer and autumn, compared to winter, albeit overall health condition is quite stable.

Taken together all evaluated data and results, there are many point and non-point water pollution sources in the TGRA that can induce threats to relatively stable ecosystem in near future. Therefore, pollutants discharges and ecological health of TGRA should be monitored on regular basis. Besides, government should strictly implement the environmental protection laws, enhance the awareness of sustainable development and maintain the balance between economic activities and ecological environment.

\section{Acknowledgement}

The authors are grateful for supports from the Hundred Talents Program of Chinese Academy of Sciences, the Key Application and Development Program of Chongqing Science and Technology Commission (Grant No. cstc2014yykfC20004), the Application and Development Program of Science and Technology Commission of Beibei District, Chongqing (2015-07), the Scientific Research Starting Foundation for Returned Overseas Chinese Scholars from Ministry of Education and the National Technology Foundation for Selected Overseas Chinese Scholar of Chongqing Human Resources and Social Security Bureau, China.

\section{Author's Contributions}

Chun-Jiao Lu and Dan Luo: Manuscript preparation, data acquisition and analysis
Muhammad Junaid: Manuscript revision.

Jin-Jing Duan: Manuscript revision.

Shi-Min Ding: Data analysis.

Ao-Xue Dai: Statistical analysis.

Tuan-Wu Cao: Data interpretation.

De-Sheng Pei: Manuscript conception and design.

\section{Conflict of Interest}

The authors declare no conflict of interest.

\section{References}

ACEDP, 2012. Taizi River health report card. Chinese Research Academy of Environmental Science, Australia-China Environment Development Partnership.

Benitez-Nelson, C., 2000. The biogeochemical cycling of phosphorus in marine systems. Earth Sci. Rev., 51: 109-135.

Constanza, R., R. D'Arge, R. De Groot, S. Farberparallel and M. Grasso, 1997. The value of the world's ecosystem services and natural capital. Nature, 387: 253-260. DOI: $10.1038 / 387253 \mathrm{a} 0$

Cui, Q., X. Wang, D. Li and X. Guo, 2012. An ecosystem health assessment method integrating geochemical indicators of soil in Zoige wetland, southwest China. Procedia Environ. Sci., 13: 1527-1534. DOI: 10.1016/j.proenv.2012.01.145

Grilfitth, M.B., B.H. Hill and F.H. McCormick, P.R. Kaufmann and A.T. Herlihy et al., 2005. Comparative application of indices of biotic integrity based on periphyton, macroinvertebrates and fish to southern Rocky Mountain streams. Ecol. Indicat., 5: 117-136. DOI: $10.1016 /$ j.ecolind.2004.11.001

Hellawell, J.M., 1986. Biological Indicators of Freshwater Pollution and Environmental Management. 1st Edn., Elsevier Applied Science Publishers, London, ISBN-10: 1851660011, pp: 546.

Hong, Y., M. Ye and X. Zang, 2004. Effects of nitrogen and phosphorus in the three gorges reservoir. China Water Resour., 20: 23-24.

Huang, S., C. Zang and S. Du, 2011. Study on the relationships among $\mathrm{pH}$, dissolved oxygen and chlorophyll a I: Aquaculture water. Chinese J. Environ. Eng., 5: 1201-1208.

Liao, J., X. Cao and J. Wang, 2014. Basin-scale aquatic ecosystem health assessment with composite indices of chemistry and aquatic biota: A case study of Dianchi Lake. Acta Sci. Circumstantiae, 34: 1845-1852.

Lin, R. and J. Wu, 1994. Yellow River Estuary of phosphate adsorption and release. Acta Oceanologica Sinica, 16: 82-89. 
Liu, P., 2007. The study of phophorus species' distribution in the Three Gorges Reservoir and the main channel of the Changjang (Yangtze River) after the filling to 135 meter. Ocean University of China.

Liu, Y. and Z. Yin, 2014. Space-time distribution of eutrophication in backwater zones of Branch Rivers in the three gorges reservoir. Environ. Protect. Sci., 4: 30-34.

Lu, C. J. Duan, M, Junaid, T. Cao, S. Ding and D. Pei, 2015. Recent status of fishes in the Yangtze River and its ecological health assessment. Am. J. Environ. Sci., 12: 86-93.

$\mathrm{Lu}, \mathrm{P}$. and W. Mi, 2011. Analysis on general variation of water quality in Chongqing reach after impoundment of Three Gorges Reservoir. Yangtze River, 42: 28-32.

Ma, K., H. Kong and W. Guang, 2001. Ecosystem health assessment methods and directions. Acta Ecol. Sinica, 21: 2016-2115.

SEPA, 2002. Water and Wastewater Monitoring and Analysis Methods Editorial Board. In: Water and Wastewater Monitoring and Analysis Methods, China Environmental Science Press, SEPA, Beijing, pp: 200-227.

SEPA, 2004-2015. Bulletin on the ecological and environmental monitoring results of the three gorges project. State Environmental Protection Administration, Beijing.

Shen, S. and B. Shi, 1996. Marine ecology. Shanghai Education Press, S.E. Press.

Silow, A.S. and O. In-Hye, 2004. Aquatic ecosystem assessment using exergy. Ecol. Indicat., 4: 189-198.

Wang, T., Q. Yang and X. Liu, 2013. Distribution of soluble in the water body heavy metal concentration Three Gorges Reservoir after its in $172 \mathrm{~m}$ impoundment. Resources Environ. Yangtze Basin, 22: 1195-1200.

Wang, X., J. Feng and M. Hu, 2004. Factor analysis and dynamics of pre-and post-dredging of Nanhu Lake in Changchun. Environ. Monitor. China, 20: 10-13.

Wei, F., J. Zhang, L.He, X. Wang, G. Wu and Z. Ding 2009. The key to prevent water pollution of the Three Gorges Reservoir Area is source control and Three Gorges abatement. Eng. Sci., 11: 4-9.

Wells, G.P., 2003. Assessing health of the Bay of Fundy: Con-Cepts and framework. Marine Pollut. Bull., 46: 1059-1077.

Wen, Z. and J. Liu, 1996. Applied ecology. Shanghai Education Press, Shanghai.

Xie, F., G. J. Gu and Z. Lin, 2014. Assessment of aquatic ecosystem health based on principal component analysis with entropy weight: A case study of Warming Reservoir (Hainan Island, China). Chinese J. Applied Ecol., 25: 1773-1779.
Xiong, W., S. Huang and X. Yang, 2010. Research on key evaluation indexes of healthy river ecological system. Yangtze River, 41: 7-12.

Xu K., S. Hayashi, S. Murakaml, H. Maki, B. Xu and M. Watanabe, 2004. Characteristics of water quality in the Changjiang river: Observations Conducted in 1998 and 1999. Acta Geographica Sinica, 59: 118-124.

$\mathrm{Xu}, \mathrm{J} ., 2005$. Variation in grain size of suspended load in upper Changjiang River and its tributaries by human activities. J. Sediment Res., 6: 8-16.

$\mathrm{Xu}, \mathrm{W}$. and $\mathrm{S}$. Xu, 2007. Entropy weight comprehensive health index method for assessment of lake ecosystem health. Res. Soil Water Conservat., 14: 66-71.

Yan, W., L. Liu and L. Song, 2008. Healthy diagnosis for ecology and environment in TGP reservoir area and countermeasure research. Yangtze River, 39: 9-12.

Yan, W., 2007. Study on ecosystem health diagnoses and water resource management mode in TGP area. MSc Thesis HoHai University.

Yan, Z., J. Tu, D. Lu, X. Yan and J. Wu, 2011. Study on the relationship between population and eco-nomic spatial distribution and its dynamic in Chongqing. Economic Geography, 31: 1781-1785

Yang, Y., 2013. Characteristics of heavy metals pollution of fishes in Daning River of Three Gorges Reservoir Area during initial impoundment. CJE, 32: 1870-1876.

Ye, S., X. Liu and D. Ding, 2007. Ecosystem health assessment of the Changjiang River Estuary: Indicator system and its primarily assessment. Acta Oceanologica Sinica, 29: 128-136.

Yin, Z. and J. Li, 2014. Variation tendencies of major pollutants concentration in mainstream of Changjiang River before and after in three gorges dam. Environ. Sci. Manage., 39: 42-45.

Zhang, Y., J. Wang, J. Liu, K. Luo and L. Han et al., 2014. Study on phosphorus release mechanism in sediments of Eutrophic water and the controlling technology. J. Hangzhou Normal Univ., 13: 53-57.

Zhang, Z. and J. Zhang, 2004. Effects of $\mathrm{pH}$ on adsorption of several metals to suspenden sediment in the Changjiang River estuary. Oceanologia Limnologia Sinica, 34: 267-273.

Zhou, Y., 2006. Summary about geography researches of Yangtze Three Gorges Area. Yunnan Geographic Environ. Res., 18: 5-9. 